\title{
REDE GEODÉSICA PARA MONITORAMENTO DE PROCESSOS DE SUBSIDÊNCIA NA PLANÍCIE DELTAICA DO RIO SÃO FRANCISCO
}

\author{
GEODESIC NETWORK FOR MONITORING SUBSIDENCE PROCESSES IN THE DELTAIC \\ PLAIN OF SÃO FRANCISCO RIVER
}

\author{
EImo Leonardo Xavier TANAJURA ${ }^{\mathbf{1}}$, Admilson da Penha PACHECO ${ }^{2}$, José Maria \\ Landim DOMINGUEZ ${ }^{3}$, Junia Kacenelenbogen GUIMARÃEES ${ }^{4}$ \\ ${ }^{1}$ Programa de Pós-Graduação em Geociências Área: Geociências/Geodésia. Universidade Federal de Pernambuco. E-mail: \\ elmo.tanajura@ufba.br \\ ${ }^{2}$ Centro de Tecnologia e Geociências Departamento de Engenharia Cartográfica, Universidade Federal de Pernambuco. Recife - PE. \\ E-mail: pacheco3p@gmail.com \\ ${ }^{3}$ Instituto de Geociências/Departamento de Oceanografia, Universidade Federal da Bahia Salvador - BA. E-mail: \\ landim.jmd@me.com \\ ${ }^{4}$ Instituto de Geociências/Departamento de Geografia, Universidade Federal da Bahia. Salvador - BA. E-mail: jkg@ufba.br
}



RESUMO - Processos de subsidência são caracterizados pelo movimento de uma porção da superfície da Terra na qual resulta no rebaixamento do terreno. Os ambientes sedimentares deposicionais, como é o caso dos deltas, são propensos à subsidência devido à compactação de sedimentos. O objetivo principal deste trabalho é o desenvolvimento de um projeto geométrico e implantação de uma rede geodésica para o acompanhamento periódico da subsidência na planície deltaica do Rio São Francisco. Cordões litorâneos holocênicos presentes na planície tiveram suas altitudes avaliadas a partir de perfis topográficos longitudinais obtidos por levantamentos GNSS (Global Navigation Satellite System). Em alguns cordões, desníveis médios na ordem de 3,2 $\mathrm{m}$ e 5,5 m foram detectados nas porções sul e norte da planície, respectivamente, sendo um indicativo de rebaixamento da superfície devido a acentuados processos de subsidência que ocorreram desde o Holoceno. As informações de rebaixamento dos cordões permitiram identificar áreas vulneráveis aos processos de subsidência, dando suporte ao projeto de uma rede geodésica composta por 26 vértices de monitoramento. Palavras-chave: Processos de subsidência. Planície deltaica do Rio São Francisco. Rede Geodésica de Monitoramento.

ABSTRACT - Subsidence processes are characterized by the movement of a portion of the Earth's surface which results in the lowering of the terrain. Depositional sedimentary environments, such as deltas, are prone to subsidence due to sediment compaction. The main objective of this work is the development of a geometric project and the implantation of a geodesic network for the periodic monitoring of subsidence in the delta plain of the São Francisco River. Holocene coastal streams present in the plain had their altitudes evaluated from longitudinal topographic profiles obtained by GNSS (Global Navigation Satellite System) surveys. In some strands, unevenness average gaps in the order of $3.2 \mathrm{~m}$ and $5.5 \mathrm{~m}$ were detected in the southern and northern portions of the plain, respectively, being an indication of the lowering of the surface due to accentuated subsidence processes that have occurred since the Holocene. The information on the lowering of the strands made it possible to identify areas vulnerable to subsidence processes, supporting the design of a geodetic network composed of 26 monitoring vertices.

Keywords: Subsidence Process. Sao Francisco River Deltaic Plain. Geodetic Network of Monitoring.

\section{INTRODUÇÃO}

Estudos de subsidência caracterizam-se por serem definidos por parâmetros individualizados e concentrados em escala regional. Os resultados, por sua vez, podem não ser comparáveis ou complementares aos de outros estudos, o que dificulta a integração das investigações para uma avaliação do fenômeno numa escala mais abrangente (Yuill et al., 2009).

Os ambientes sedimentares deposicionais, como é o caso dos deltas, são propensos à subsidência devido à compactação de sedimentos. Estes ambientes são construídos, primariamente, pelo depósito de sedimentos a partir de um sistema fluvial. Com o passar do tempo, o volume dos 
sedimentos depositados diminui naturalmente e, nesse processo de acomodação, acaba resultando numa compactação e, consequentemente, a subsidência.

A existência de regiões constantemente inundadas na planície deltaica do Rio São Francisco, localizada nos estados de Sergipe e Alagoas, sugere a existência de subsidência nesta região. Guimarães (2010) conduziu investigações baseadas em informações estratigráficas juntamente com datações realizadas na planície. Resultados apresentaram uma significativa disparidade entre as altitudes de amostras com a mesma idade, o que caracteriza um forte indicativo de que processos de subsidência estão ocorrendo na região. A evolução quaternária da planície foi fortemente controlada por sucessivas variações relativas do nível do mar durante este período, conforme demonstrado em diversos estudos (Martin et al., 1979; Bittencourt et al., 1982, 1983; Barbosa, 1985; Barbosa et al., 1986; Barbosa, \&; Villwock et al., 1986; Leão \& Dominguez, 2000; Dominguez \& Araújo, 2008).

A Geodésia Espacial, que na era moderna revolucionou as técnicas de posicionamento, tem sido uma efetiva ferramenta em atividades de monitoramento. O Global Navigation Satellite System (GNSS), Very Long Baseline Interferometry (VLBI) e o Satellite Laser Ranging (SLR), permitem estimar, com precisão milimétrica, a posição tridimensional de pontos de redes geodésicas de monitoramento, podendo ser utilizadas como fontes de informações nos estudos de deformações da crosta.

Segundo Teixeira (2005), isso pode ser comprovado pelo crescente número de estudos desta natureza, os quais utilizam campos de deslocamentos provenientes destas técnicas, mostrando o quão valioso e importante papel elas representam na mensuração de fenômenos geodinâmicos. Monitoramento de processos de subsidência utilizando o GNSS foram abordados em estudos desenvolvidos por Sato et al. (2003), Baldi et al. (2009), Dos Santos et al. (2012) e Steckler et al. (2013).

O GNSS, conjunto das constelações de satélites artificiais de posicionamento, tem sido a principal ferramenta da atualidade utilizada em atividades que envolvam o posicionamento de um modo geral. Posicionar um objeto em Geodésia consiste em atribuir-lhe coordenadas com o propósito de vinculá-lo a um sistema de referência pré-estabelecido. Portanto, as aplicações do GNSS são inúmeras, e vêm crescendo continuamente em atividades de geodinâmica, navegação global e regional, estabelecimento de redes geodésicas locais, regionais, continentais e globais (ativas e passivas), para determinações altimétricas além de levantamentos geodésicos para fins de mapeamento, monitoramento e controle de deformações (Leick et al., 2015; Monico, 2008; Seeber, 2003). Estudos realizados em diversas modalidades têm mostrado que a subsidência pode ser mensurada e monitorada com precisão milimétrica, utilizando a técnica do GNSS (Silva et al, 2015). Outros autores utilizaram GNSS em aplicações geodinâmicas (Drewes \& Heidbach, 2012; Marjanović, et al., 2012; Monico, 2000; Song \& Yun, 2006; Souza, 2013).

A avaliação temporal das coordenadas num monitoramento de subsidência com GNSS consiste em quantificar os deslocamentos de pontos na superfície física da Terra numa escala de tempo a partir das variações das suas coordenadas tridimensionais no espaço em função do sistema geodésico de referência adotado.

Devido à formulação espacial do problema, utilizam-se, na Geodésia, os sistemas de referência tridimensionais. Um sistema terrestre, por exemplo, pode ser usado para determinar posições e o campo de gravidade quando fixado em relação à Terra. Isso pode ser descrito num sistema cartesiano global de coordenadas espaciais. Para aplicações em levantamentos geodésicos, bem como em outras atividades, as altitudes são definidas no campo gravitacional terrestre e associadas ao geoide como referência zero. (Torge et al., 2012).

Um ponto na superfície física da Terra pode ser representado pelo terno cartesiano de coordenadas geocêntricas $(\mathrm{X}, \mathrm{Y}, \mathrm{Z})$, onde a origem do sistema localiza-se no centro de um elipsoide de revolução que, para o caso do GNSS, coincide com o centro de massa da Terra (geocentro) (Figura 1).

Seja um ponto $\mathrm{P}$ localizado na superfície física da Terra e projetado no elipsoide de revolução ao longo da reta normal. Suas coordenadas geodésicas $(\varphi \mathrm{P}=$ latitude e $\lambda \mathrm{P}=$ longitude $)$ relacionam-se com as respectivas componentes cartesianas (XP, YP, ZP) num sistema cartesiano geocêntrico. Atualmente, com a definição de um sistema geodésico moderno, as informações a ele 
vinculadas, são definidas e materializadas de maneira que as coordenadas tridimensionais dos vértices que o compõe estejam relacionadas a uma determina época, tornando-os assim uma referência espaço-temporal.
Neste contexto, este trabalho tem como objetivo o estabelecimento de uma rede de vértices geodésicos para o monitoramento periódico dos processos de subsidência da Planície Deltaica do Rio São Francisco.

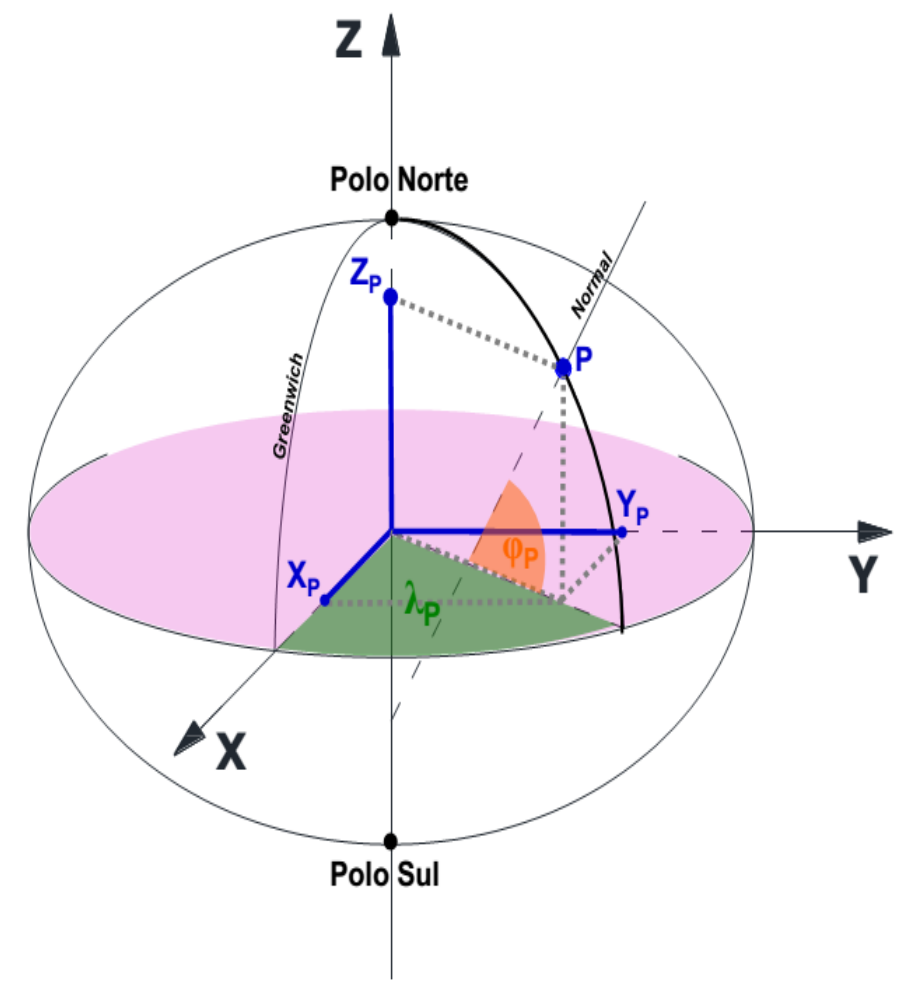

Figura 1 - Relação entre as coordenadas num sistema cartesiano geocêntrico.

\section{ÁREA DE ESTUDO}

A área de estudo corresponde à planície deltaica associada à desembocadura do Rio São Francisco, situada na Bacia Sedimentar Sergipe-Alagoas. Esta bacia se apresenta na forma de um graben que se alinha na direção NE-SW, mergulhando para sudeste. A planície deltaica do Rio São Francisco é composta por depósitos pleistocênicos e holocênicos, sendo delimitada por sedimentos clásticos terciários da Formação Barreiras, discordantes sobre as rochas mais antigas. Os depósitos presentes no limite noroeste possuem formato tabular com espessuras variando de 20 a
$30 \mathrm{~m}$, onde recobrem a borda da bacia e alcançam espessuras de 100 a $120 \mathrm{~m}$ nas proximidades do litoral (Ponte, 1969; Guimarães, 2010; Dominguez \& Araújo, 2008). O Delta do São Francisco é um dos mais proeminentes da costa brasileira, se estendendo por uma linha de costa de cerca de 75 $\mathrm{km}$ e abrangendo uma área de aproximadamente 800 km2 (Guimarães, 2010; Ponte, 1969) (Figura 2). A região compreende os municípios de Feliz Deserto, Piaçabuçu e Penedo, no Estado de Alagoas, e Neópolis, Ilha das Flores, Brejo Grande, Pacatuba e Parambu no Estado de Sergipe.

\section{MATERIAIS E MÉTODOS}

A ocorrência de processos sedimentares de subsidência transcorre devido às movimentações dos pacotes de sedimentos depositados ao longo dos anos na planície deltaica. As constatações dos deslocamentos foram realizadas diretamente na topografia dos cordões litorâneos holocênicos mapeados na planície a partir de perfis longitudinais altimétricos de relevo oriundos de levantamentos GNSS em modo cinemático.

Os pontos definidores do relevo da planície deltaica foram obtidos através do método relativo cinemático de levantamento GNSS. Os métodos cinemáticos caracterizam-se pelo rastreio dos pontos de interesse através de uma (ou várias) estação itinerante composta de receptor e antena GNSS que percorrerá uma trajetória coletando as informações de posicionamento num intervalo de tempo pré-estabelecido. Essas informações são armazenadas no receptor e processadas posteriormente. 


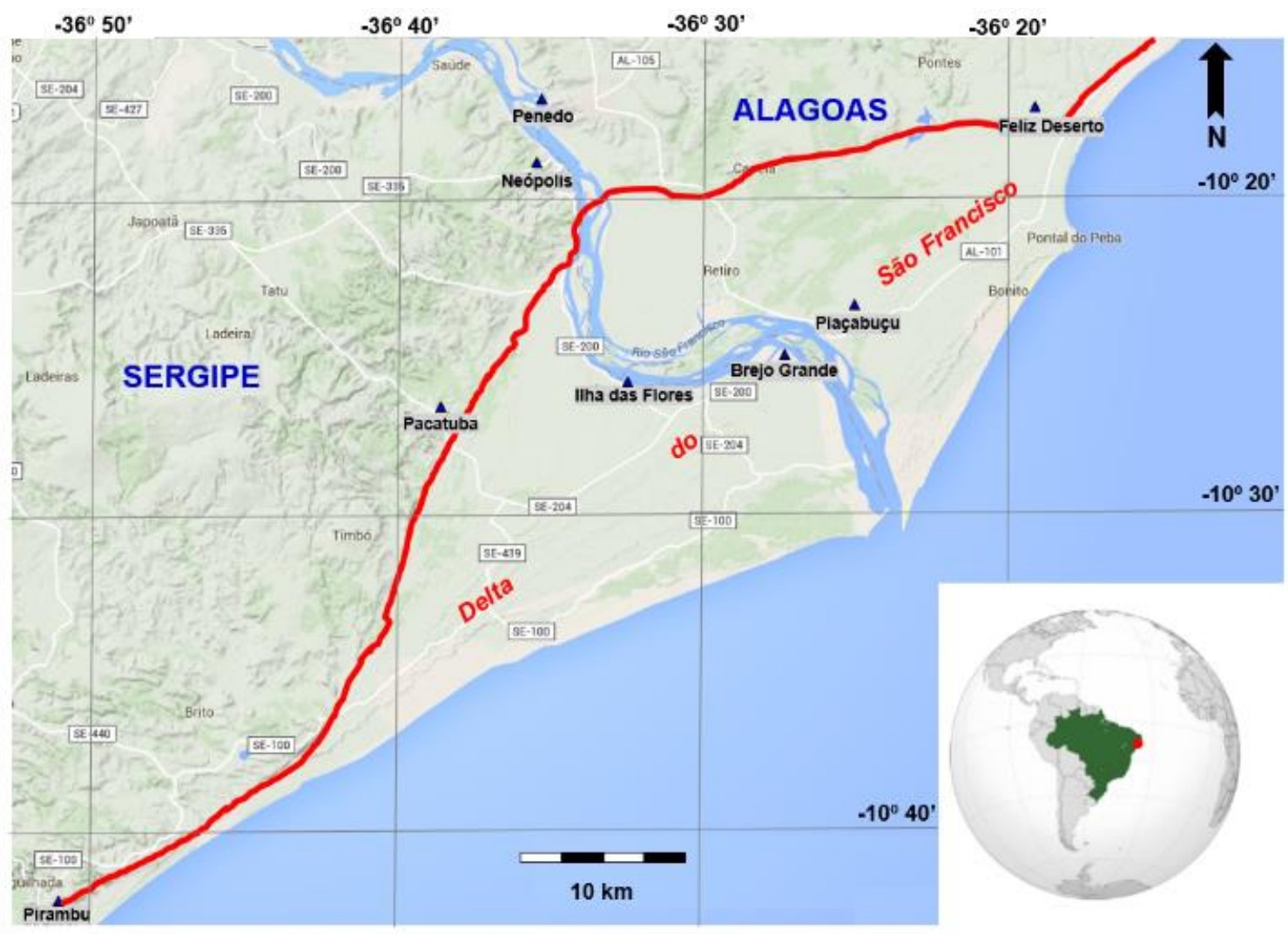

Figura 2 - Relação entre as coordenadas num sistema cartesiano geocêntrico (Adaptado de Google Maps 2018).

Os rastreios foram realizados com a estação itinerante coletando informações simultaneamente com receptores instalados em modo estático nas bases fixas, situadas em estações de referência previamente implantadas.

As estações itinerantes foram montadas em


quatro modalidades diferentes (Figura 3), e os rastreios efetuados por meio de veículos ou caminhamento com bastão.

Conforme a ocasião, uma modalidade específica foi adotada para a execução dos levantamentos.
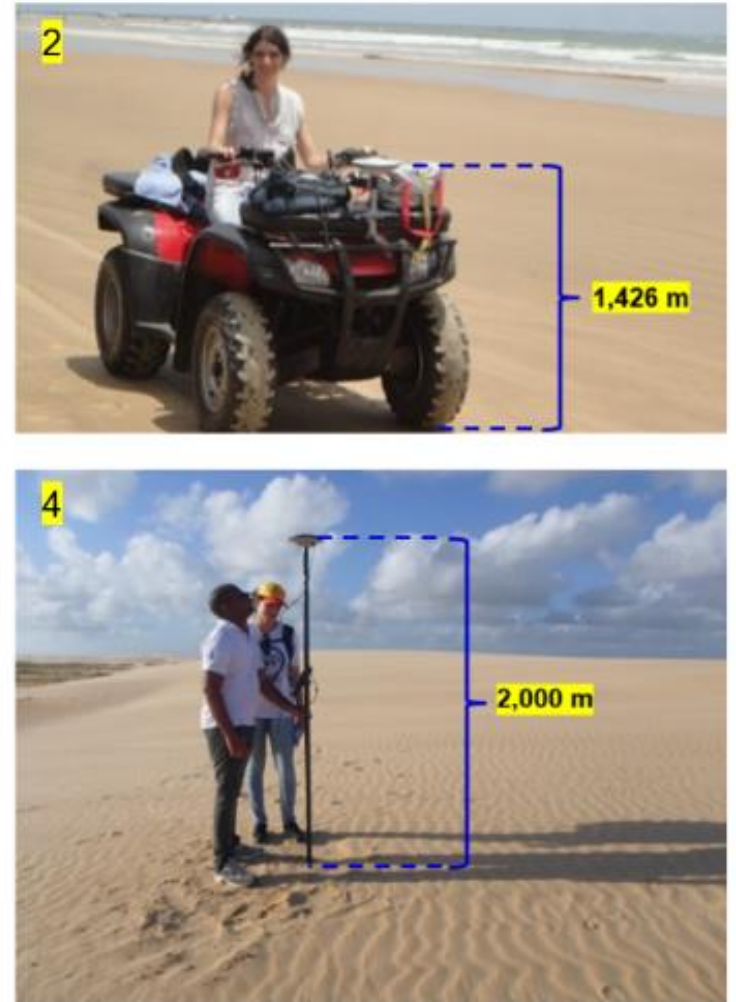

Figura 3 - Modalidades das estações itinerantes: (1) caminhonete, (2) quadricíclo, (3) motocicleta e (4) caminhamento com bastão. 
Para a obtenção das coordenadas finais dos pontos rastreados, os dados oriundos dos levantamentos cinemáticos passam por uma etapa de pós-processamento. As informações coletadas durante o rastreio, com intervalo de tempo de 1 segundo, são processadas em software de processamento GNSS. As altitudes geométricas (h) resultantes do processamento GNSS foram convertidas em altitudes ortométricas $(\mathrm{H})$. Para isso, utilizou-se o modelo de ondulações geoidais MAPGEO2010 (IBGE, 2010).

\section{RESULTADOS E DISCUSSÕES}

A planície deltaica do São Francisco é formada por sedimentos depositados em vários estágios do quaternário. As flutuações do nível relativo do mar, associadas a variações climáticas nesse período, desempenharam um papel fundamental para estabelecer a configuração atual dessa planície. Essas variações eustáticas contribuíram, entre outros aspectos, para a formação dos terraços marinhos que são os depósitos mais abundantes, e que de certa forma, definem os principais elementos geomorfológicos da feição deltaica.

Os cordões litorâneos são elementos facilmente distinguíveis nas imagens Landsat ETM+ por se tratarem de feições com um padrão aproximadamente linear e que materializam o traçado das antigas linhas de costa do período em que foram depositados. Partindo dessa premissa, admite-se que um mesmo cordão, por ter sido depositado numa época específica, teria que conservar a mesma altitude (ou valores próximos) ao longo do seu traçado. Caso sejam identificados trechos de um mesmo cordão com altitudes consideravelmente inferiores às demais, é possível que a superfície nas imediações desse segmento tenha sido afetado pela subsidência.

\section{Avaliação dos Perfis}

As avaliações das altitudes ortométricas de alguns cordões holocênicos localizados nas duas porções da planície, foram realizadas a partir da verificação das altitudes dos perfis longitudinais que cruzam essas feições (Figura 4).

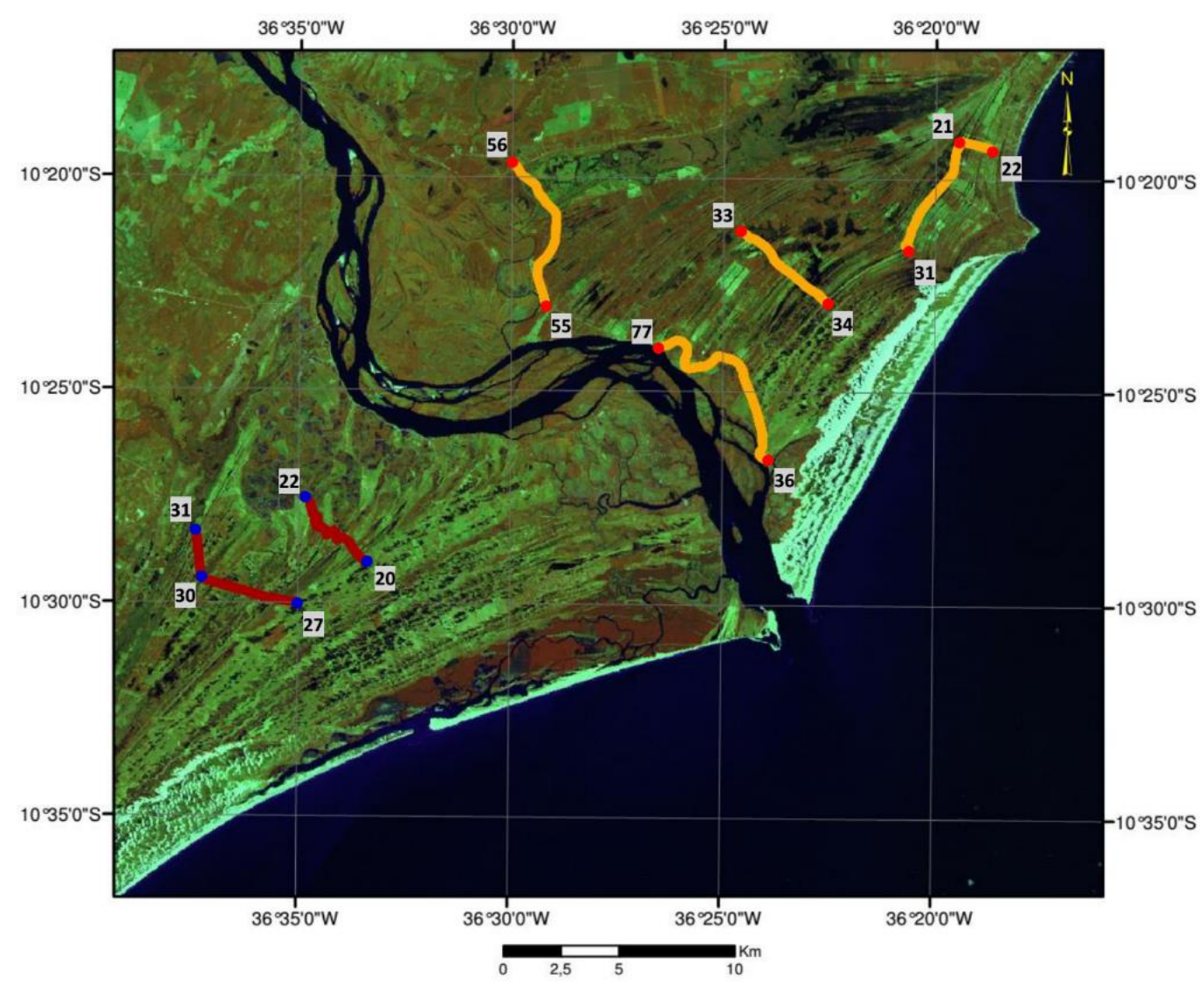

Figura 4 - Perfis longitudinais cruzando os cordões litorâneos holocênicos.

Ao todo, 8 perfis foram isolados do conjunto de alinhamentos. As avaliações a seguir propõem a verificação da conformidade topográfica de alguns terraços holocênicos em ambas porções da planície. As investigações consistem em identificar, na imagem de satélite, um traçado bem definido de cordões litorâneos e coletar uma amostragem de pontos (obtidos pelos rastreios 
cinemáticos) nos locais que os perfis longitudinais cruzam os cordões escolhidos. Sobre essa amostragem de pontos (delimitada nos perfis por retângulos azuis) é realizada uma média aritmética das respectivas altitudes, definindo assim um único valor que represente a altitude do local estabelecido.

Avaliação dos Perfis PAL 35-36, PAL 33-34, PAL 21-30, PAL 21-22

Esta análise consiste em investigar um extenso cordão (denominado Cordão A), disposto na porção norte da Planície Deltaica. A seguir, a distribuição espacial dos alinhamentos que cruzam este cordão (Figura 5).

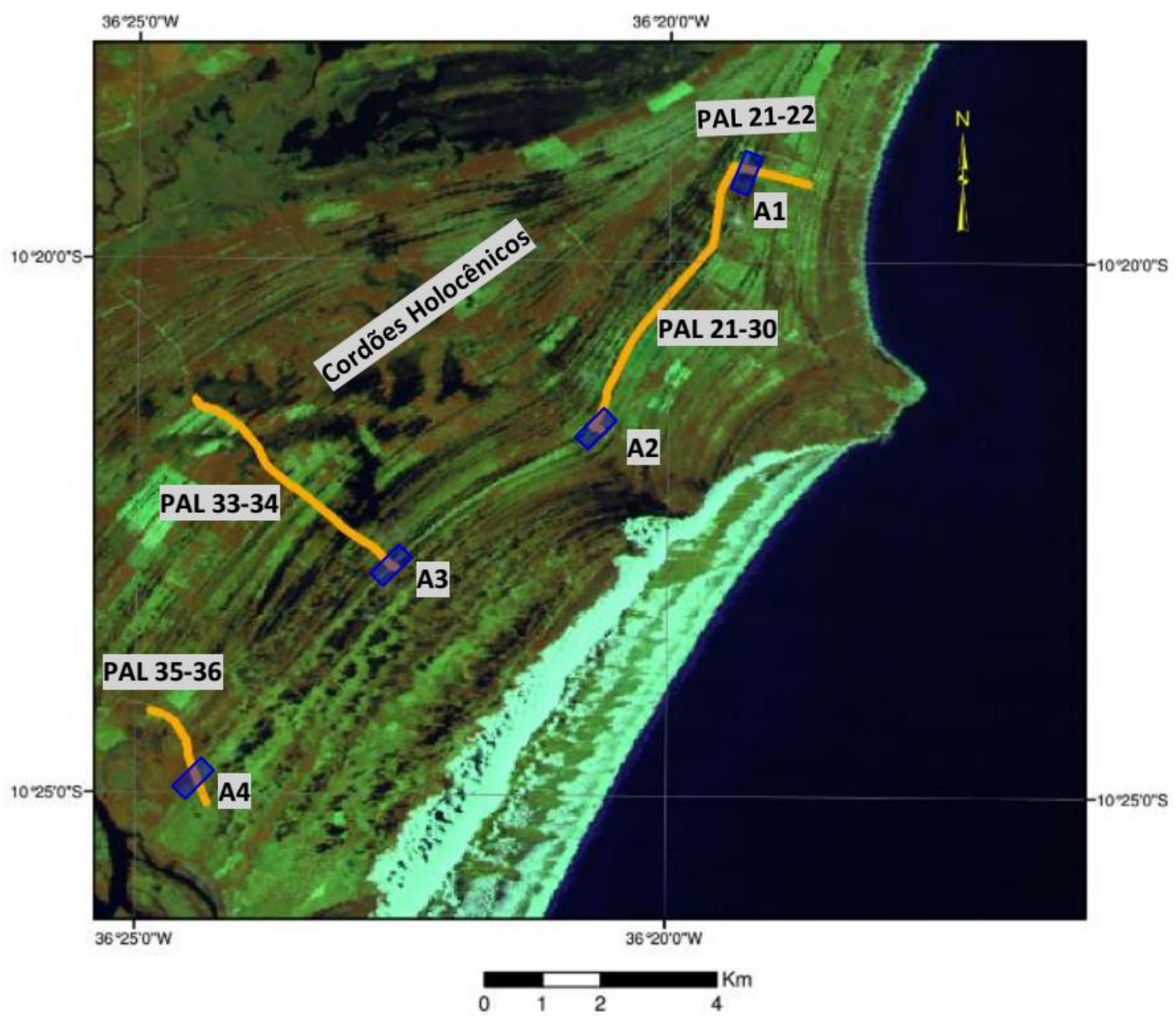

Figura 5 - Perfis PAL 35-36, 33-34, 21-30 e 21-22 cruzando cordões holocênicos.

Foram selecionados 4 trechos sobre o Cordão A (1, 2, 3 e 4), cada trecho está posicionado sobre um dos alinhamentos avaliados. A Tabela 1, a seguir, apresenta as altitudes médias dos trechos 1 a 4, na sequência, o Perfil Longitudinal de cada alinhamento (Figura 6).

Tabela 1 - Altitudes médias de trechos dos perfis PAL 35-36, 33-34, 21-30 e 21-22.

\begin{tabular}{c|c|c|c|c}
\hline \multirow{4}{*}{ Cordão } & \multicolumn{4}{|c}{ Altitudes Médias } \\
\cline { 2 - 5 } & $\mathbf{1}$ & $\mathbf{2}$ & $\mathbf{3}$ & $\mathbf{4}$ \\
\cline { 2 - 5 } & PAL 21- & PAL 21- & PAL 33- & PAL 35- \\
& $\mathbf{2 2}$ & $\mathbf{3 0}$ & $\mathbf{3 4}$ & $\mathbf{3 6}$ \\
\hline $\mathbf{A}$ & $4,3 \mathrm{~m}$ & $5,8 \mathrm{~m}$ & $5,3 \mathrm{~m}$ & $4,7 \mathrm{~m}$ \\
\hline
\end{tabular}

De uma maneira geral, as altitudes se mantiveram equivalentes ao longo de cada alinhamento avaliado, pois as extremidades do perfil conservaram valores na mesma ordem de grandeza. Entretanto, um desnível de 1,5 m foi constatado no intervalo A1 e A2, o que pode caracterizar uma subsidência pontual nesse trecho.

Avaliação dos perfis PAL 77-36, PAL 33-34

Esta análise consiste em avaliar a topografia de 4 cordões holocênicos (B, C, D e E), também dispostos na porção norte da Planície Deltaica. Os Alinhamentos PAL 77-36 e PAL 33-34 cruzam esses cordões. A figura 7 apresenta a distribuição espacial dos alinhamentos na planície deltaica.

Nesta análise, selecionou-se 4 trechos por alinhamento, 8 no total. A Tabela 2 apresenta as altitudes médias dos trechos em cada um dos 4 cordões holocênicos (B, C, D e E), na sequência, o Perfil Longitudinal dos respectivos alinhamentos (Figura 8). 
Tabela 2 - Altitudes médias de trechos dos perfis PAL 36-77 e PAL 33-34.

\begin{tabular}{c|c|c}
\hline \multirow{2}{*}{ Cordões } & \multicolumn{2}{|c}{ Altitudes Médias } \\
\cline { 2 - 3 } & $\mathbf{1}$ & $\mathbf{2}$ \\
\cline { 2 - 3 } & PAL 33-34 & PAL 36-77 \\
\hline B & $4,6 \mathrm{~m}$ & $3,1 \mathrm{~m}$ \\
\hline $\mathbf{C}$ & $9,2 \mathrm{~m}$ & $3,7 \mathrm{~m}$ \\
\hline D & $10,2 \mathrm{~m}$ & $3,5 \mathrm{~m}$ \\
\hline E & $12,2 \mathrm{~m}$ & $3,8 \mathrm{~m}$ \\
\hline
\end{tabular}

Esta avaliação fornece um forte indicativo de rebaixamento dos cordões no sentido NE-SW. Ainda que os desníveis obtidos estejam bastante acentuados (média de $-5,5 \mathrm{~m}$ ), provavelmente, por conta de uma possível elevação na superfície cortada pelo PAL 33-34 (mais detalhes na seção 4.5), admite-se um rebaixamento dos cordões no sentido da NE-SW, visto que as altitudes dos trechos avaliados em PAL 36-77 são relativamente baixas (3,5 $\mathrm{m}$ em média).

O rebaixamento da superfície nas imediações da sede de Piaçabuçu também pode ser visualizado na concavidade existente no gráfico do Perfil Longitudinal de PAL 36-77 (Figura 8), no trecho que é definido pelos Limites 1 e 2 no gráfico.
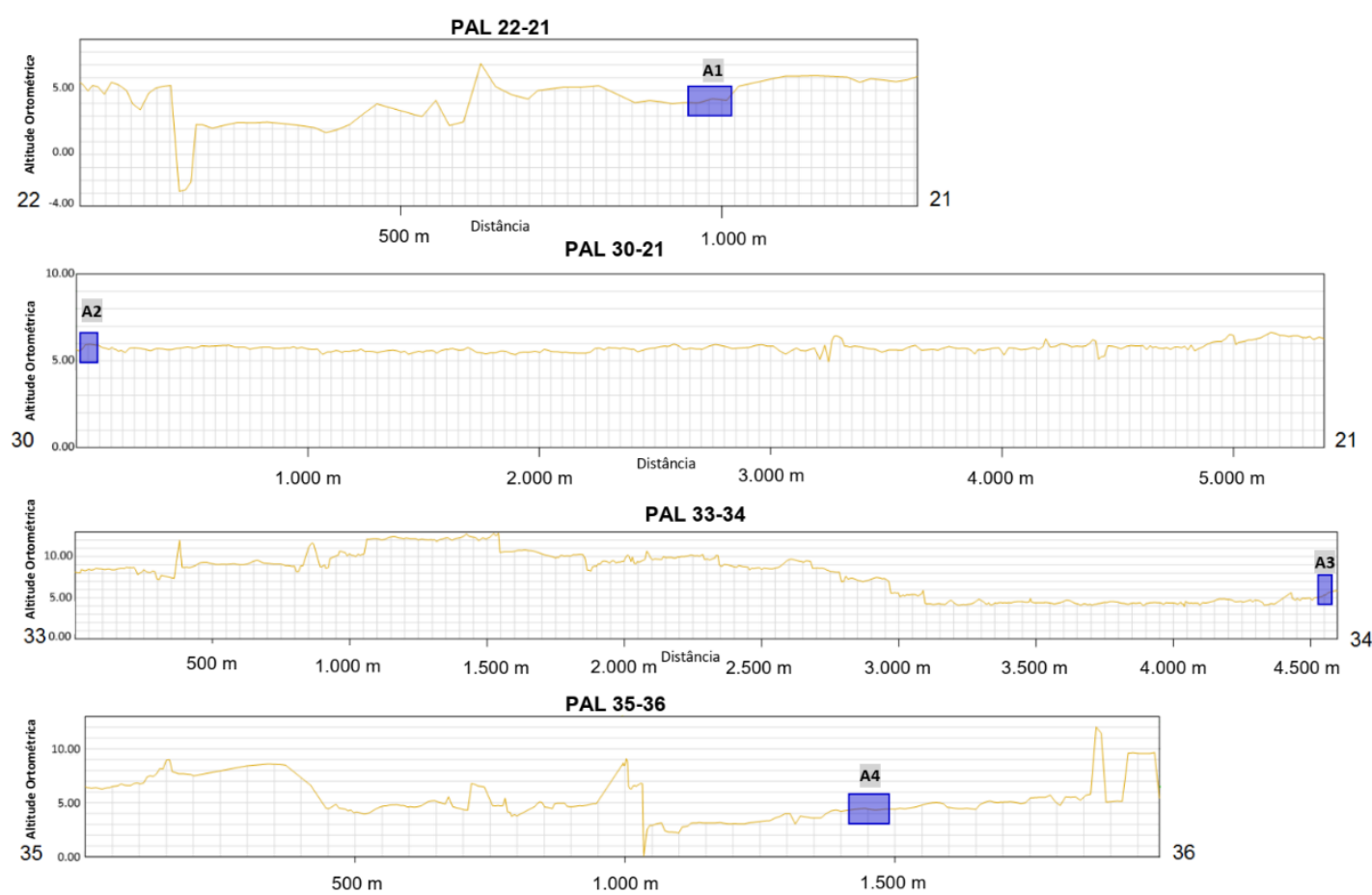

Figura 6 - Perfis Longitudinais dos Alinhamentos PAL 21-22, 21-30, 33-34 e 35-36.

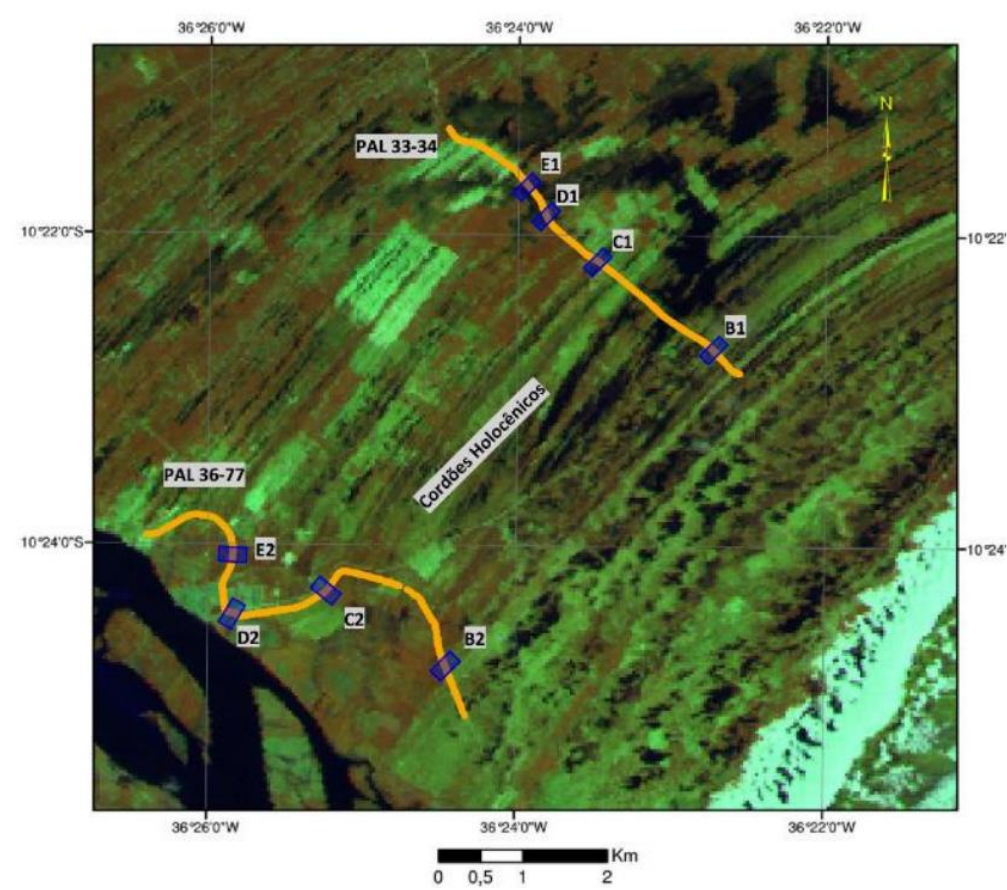

Figura 7 - Perfis PAL 36-77 e 33-34 cruzando cordões holocênicos. 

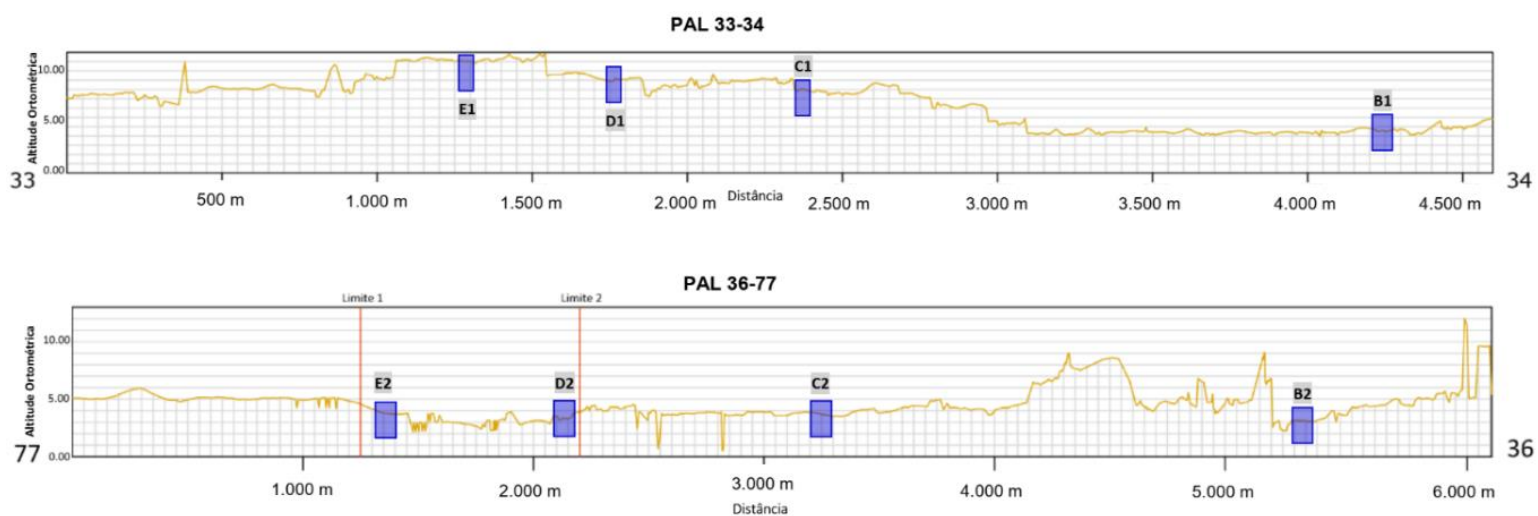

Figura 8 - Longitudinais dos Alinhamentos PAL 33-34 e 36-77.

Avaliação dos Perfis PSE 27-30 e PAL 20-22

Nesta análise, avaliou-se um cordão (denominadado Cordão F), disposto na porção sul da Planície Deltaica.

A seguir, a distribuição espacial dos alinhamentos PSE 27-30 e 20-22 que cruzam este cordão (Figura 9).

Nesta análise, selecionou-se 2 trechos ao longo do alinhamento. A Tabela 3 apresenta as altitudes médias dos trechos 1 e 2 no Cordão $\mathrm{F}$, na sequência, o Perfil Longitudinal do respectivo alinhamento (Figura 10).

Tabela 3- Altitudes médias de trechos dos perfis PSE 27-

\begin{tabular}{c|c|c}
\multicolumn{2}{c}{30 e $20-22}$. \\
\hline \multirow{3}{*}{ Cordões } & \multicolumn{2}{|c}{ Altitudes Médias } \\
\cline { 2 - 3 } & $\mathbf{1}$ & $\mathbf{2}$ \\
\cline { 2 - 3 } & PSE 27-30 & PAL 20-22 \\
\hline F & $6,3 \mathrm{~m}$ & $3,1 \mathrm{~m}$ \\
\hline
\end{tabular}

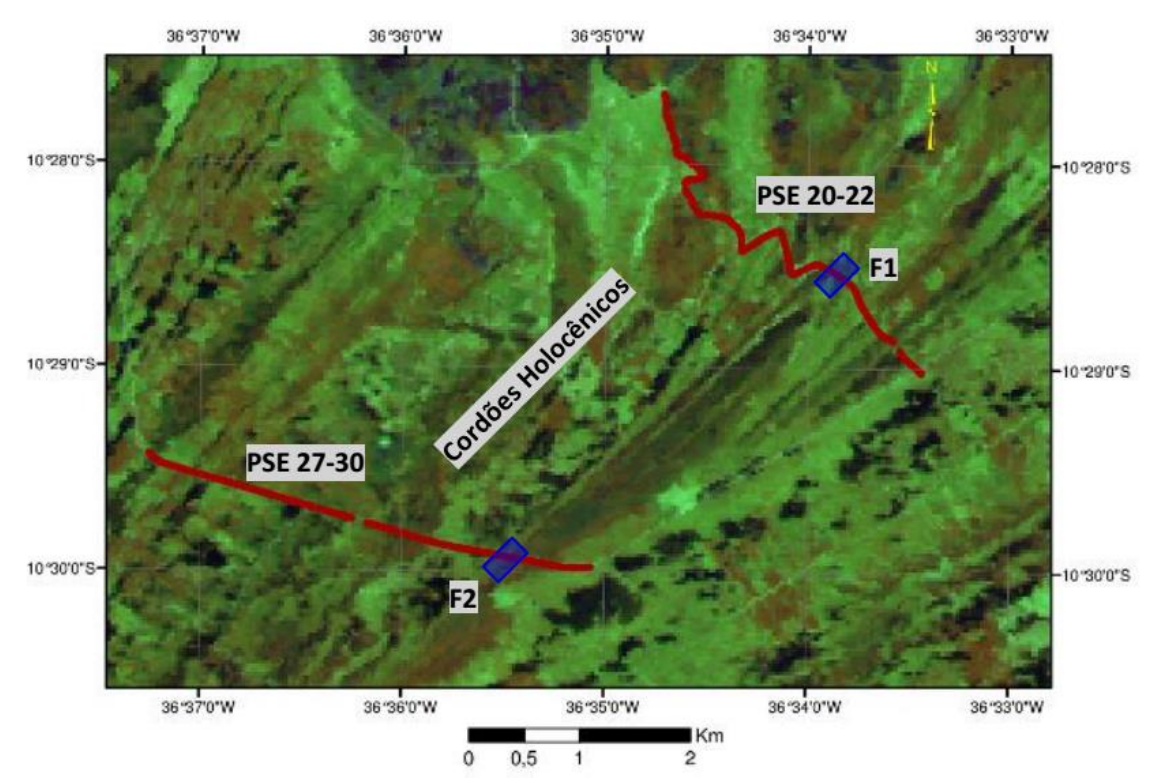

Figura 9 - Perfis PSE 27-30 e 20-22 cruzando cordões holocênicos.

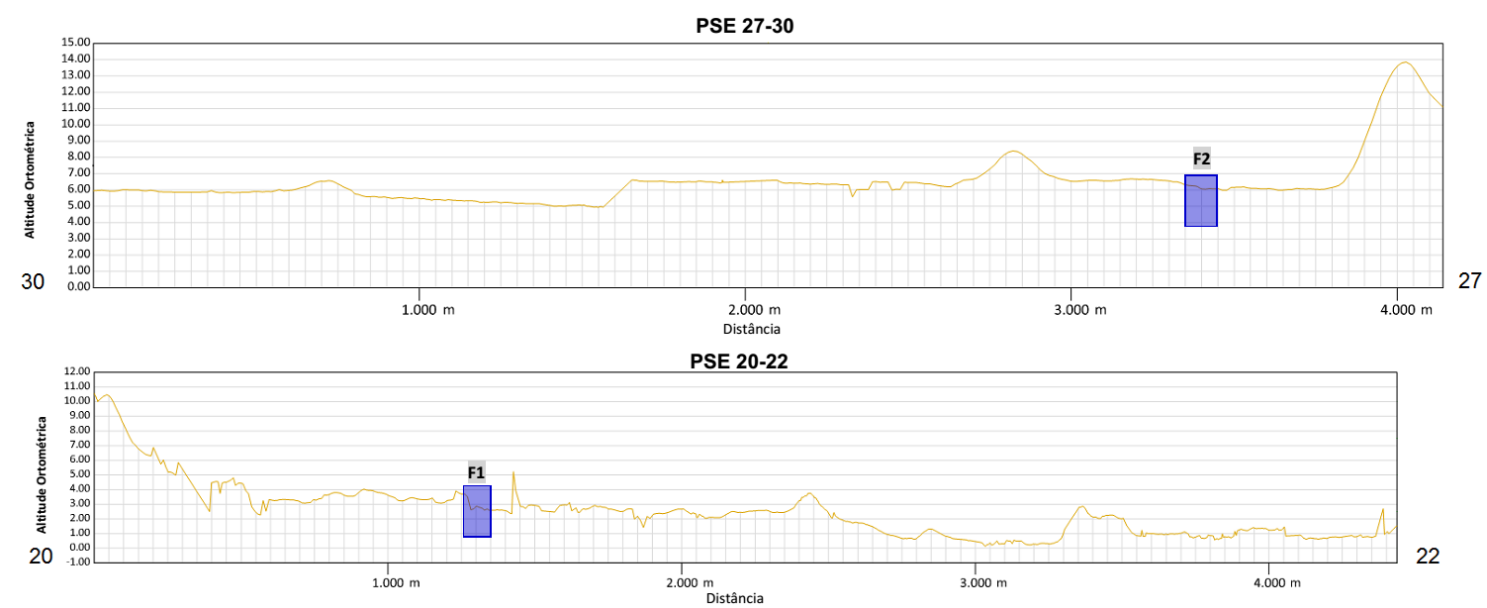

Figura 10 - Perfis Longitudinais PAL 27-30 e 20-22. 
Poucas análises foram realizadas envolvendo os cordões holocênicos do na porção sul da planície, pois, em sua grande maioria, os cordões encontram-se encobertos pelas dunas ativas e inativas.

No intervalo investigado do Cordão $\mathrm{F}$, o desnível encontrado foi de -3,2 m na direção SWNE, caracterizando também um possível rebaixamento da superfície nesse local.

\section{Avaliação dos Perfis PSE 30-31, PAL 55-56}

Esta análise investiga a subsidência em locais mais internos da planície deltaica, ou seja, mais próximo dos depósitos da Formação Barreiras. Para isso, buscou-se correlacionar um pequeno grupo de cordões holocênicos remanescentes na porção sergipana da planície com seus homólogos na outra porção. Como as extremidades dos cordões mais internos da planície, nas proximidades do Rio São Francisco, deram lugar a depósitos fluviais, buscou-se identificar os homólogos baseado na orientação dos mesmos (Figura 11).

A Figura 12 apresenta a disposição dos alinhamentos sobre o grupo de Cordões G.

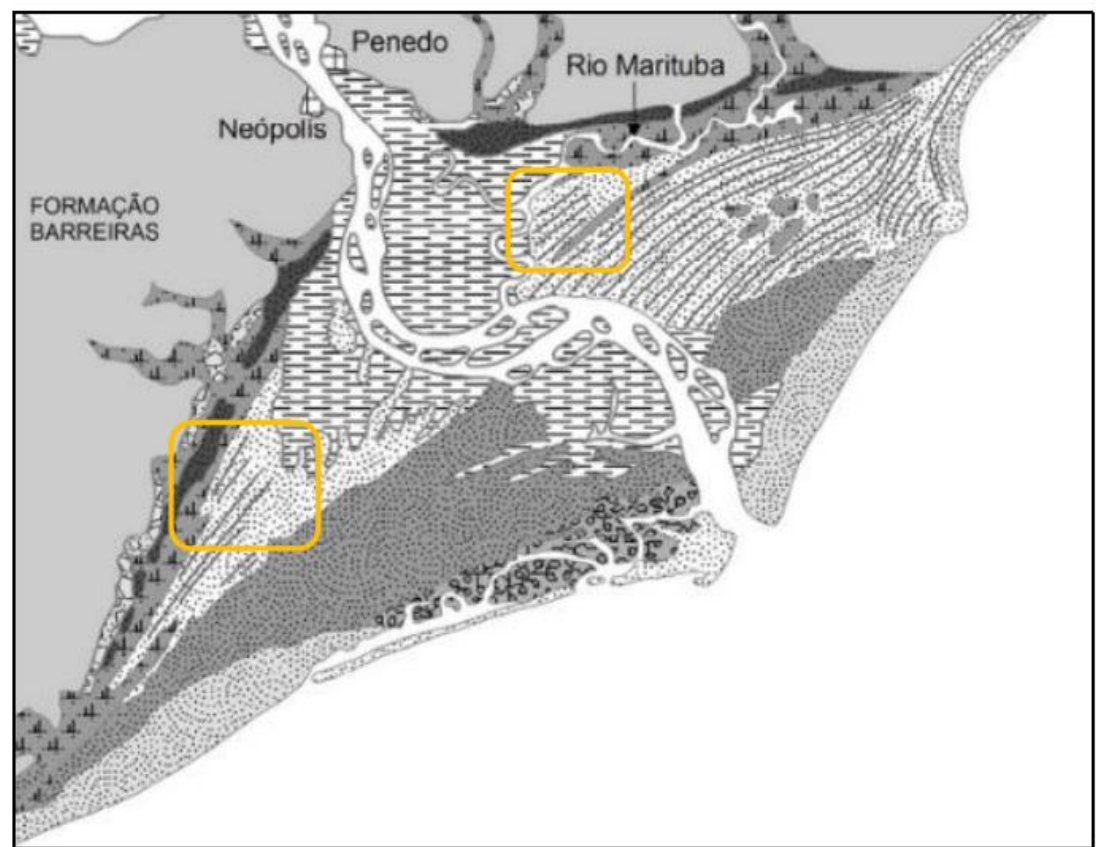

Figura 11 - Grupos de cordões holocênicos próximos aos depósitos da Formação Barreiras. Fonte: Adaptado de Guimarães (2010).

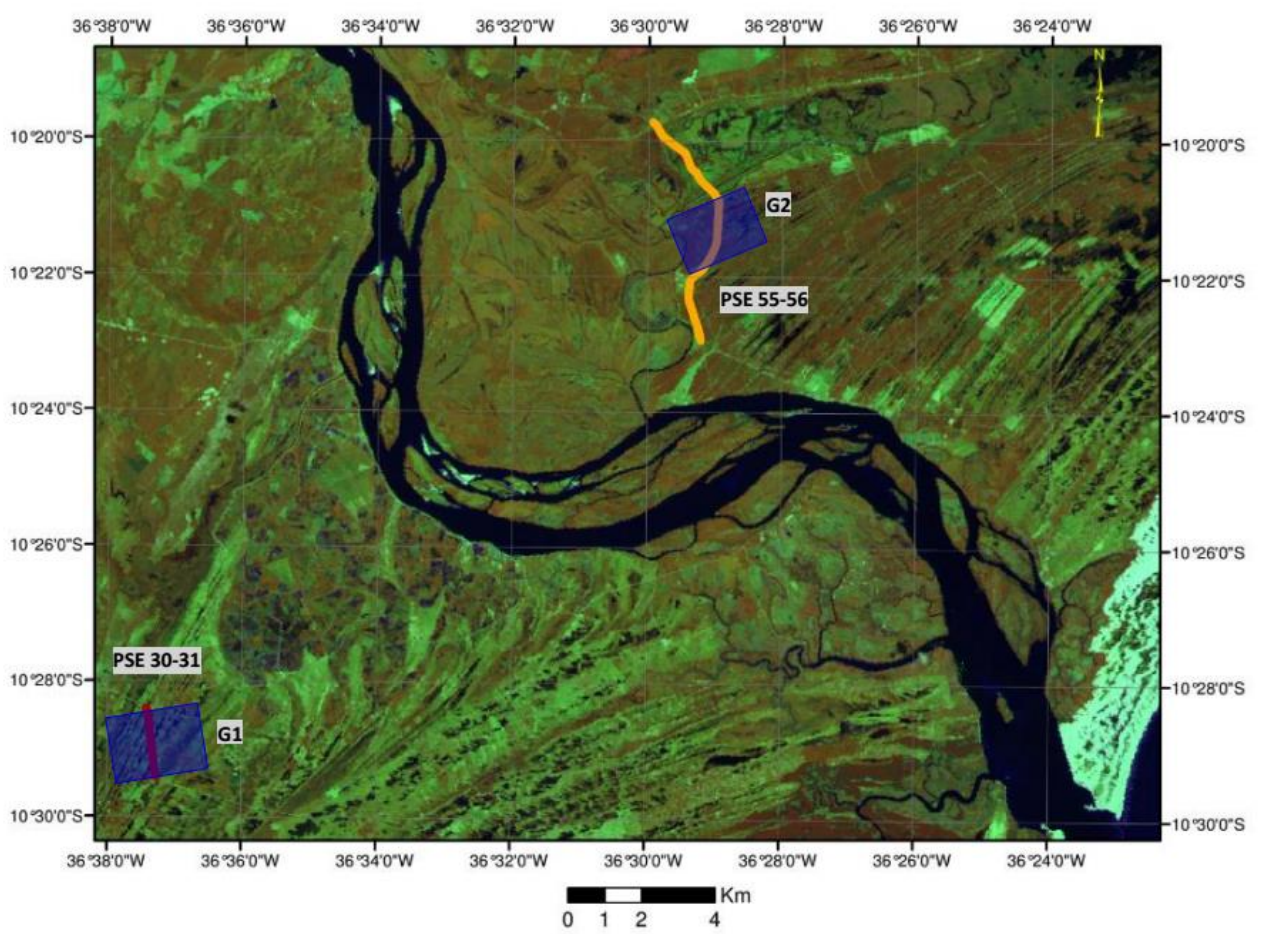

Figura 12 - Perfis PSE 31-30 e PAL 55-56 cruzando cordões holocênicos. 
Nesta análise, selecionou-se 2 trechos de alinhamento dispostos sobre o grupo de cordões G. A Tabela 3 apresenta as altitudes médias dos trechos 1 e 2 neste cordão, na sequência, o Perfil Longitudinal dos respectivos alinhamentos (Figura 13).

Tabela 4- Altitudes médias de trechos dos perfis PSE 3031 e PAL 55-56.

\begin{tabular}{c|c|c}
\hline \multirow{2}{*}{ Cordões } & \multicolumn{2}{|c}{ Altitudes Médias } \\
\cline { 2 - 3 } & $\mathbf{1}$ & $\mathbf{2}$ \\
\cline { 2 - 3 } & PSE 30-31 & PAL 55-56 \\
\hline G & $5,8 \mathrm{~m}$ & $6,8 \mathrm{~m}$ \\
\hline
\end{tabular}

A falta de continuidade dos segmentos não permitiu que fosse realizada uma identificação individual das feições com seus homólogos e, por conseguinte, uma associação em bloco foi realizada estabelecendo-se, assim, uma amostragem maior de pontos numa faixa mais larga de cordões.

Sendo assim, as altitudes médias dos cordões avaliados, 5,8 m e 6,8 m para os trechos $\mathrm{G} 1$ e G2, respectivamente, podem, de certa forma, ser consideradas equivalentes.

Nesse caso, admite-se que nessa região da planície deltaica os processos de subsidência foram inexistentes ou insignificantes diante das informações avaliadas.
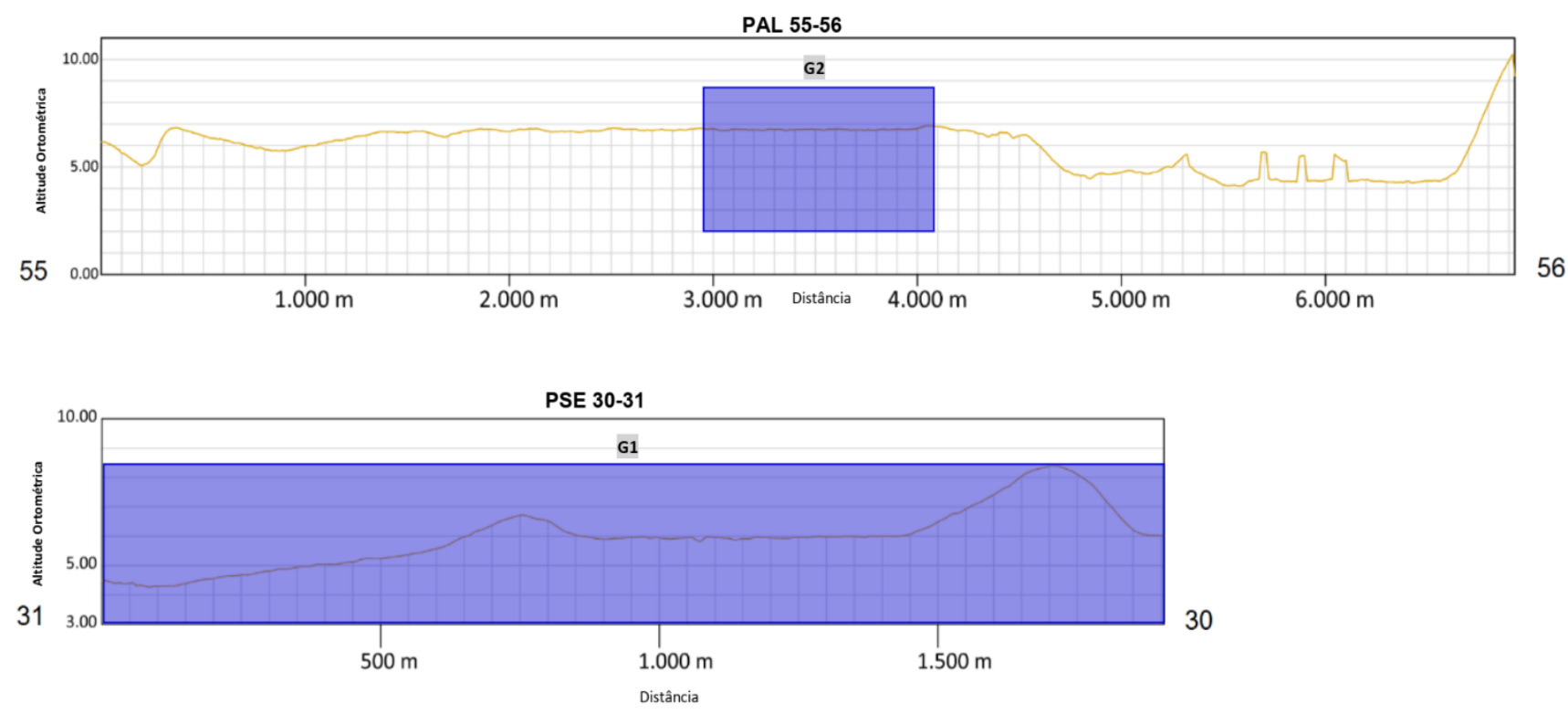

Figura 13 - Perfis longitudinais PSE 30-31 e PAL 55-56.

\section{Avaliação do Perfil PSE 33-34}

Nesta análise, apenas o perfil do alinhamento PAL 33-34 foi investigado em todo o seu percurso. Este perfil possui a particularidade de percorrer cerca de $4,5 \mathrm{~km}$ cruzando, perpendicularmente, diversos cordões holocênicos que passam nas denominadas zonas úmidas, localizadas na parte central da porção norte da planície deltaica (Figura 14), na sequência, o Perfil longitudinal do alinhamento PAL 33-34 (Figura 15).

É possível observar duas situações distintas ao longo deste perfil longitudinal. A primeira é relativa ao intervalo compreendido entre os Limites 1 e 2 (Figuras 14 e 15) que possui suas altitudes consideravelmente inferiores ao restante do segmento. Em média, essas altitudes definem um plano de 4,4 m. A segunda situação diz respeito ao aclive que se inicia após o Limite 1, no perfil longitudinal (Figura 15), promovendo uma elevação da altitude média a 9,5 $\mathrm{m}$ até o término do alinhamento. Considerando que existem terraços pleistocênicos nas imediações da Formação Barreiras, com altitudes em torno de 7 m (de acordo com uma Referência de Nível do IBGE implantada num terraço pleistocênico RN2543D $\mathrm{H}=7,243 \mathrm{~m}$ ), admite-se que no Quaternário, o nível do mar na planície deltaica alcançara, no máximo, altitudes em torno de 7 metros. Logo, não se justifica que esses cordões holocênicos possuam altitudes relativamente tão elevadas (9,5 m metros em média), exceto, se um outro fator geológico tenha proporcionado tal suspensão. $\mathrm{O}$ trecho com as altitudes elevadas poderia ser justificado por um intenso retrabalhamento eólico ocorrido nessa localidade. No entanto, as cristas e vales presentes nos cordões litorâneos, ao longo do trecho suspenso, contradizem com essa suposição. 


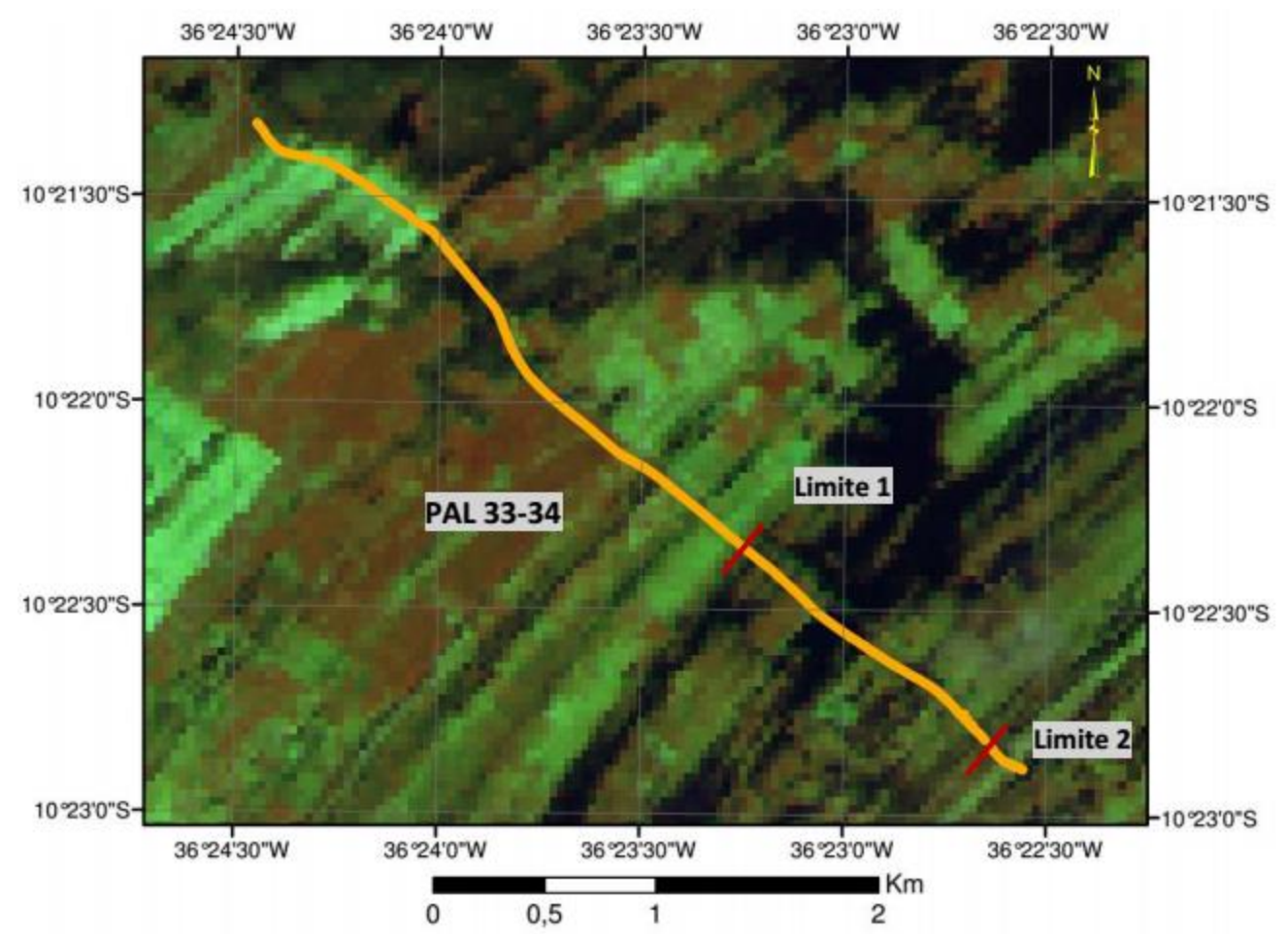

Figura 14 - Perfil PAL 33-34 cruzando cordões holocênicos.

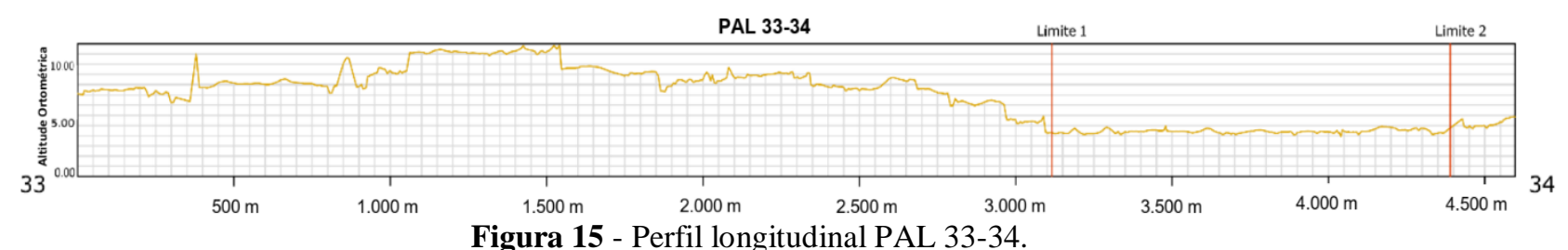

Rede Geodésica para Monitoramento da Subsidência

As constatações de rebaixamentos nos cordões holocênicos na planície, detectadas nas investigações realizadas, embasaram o projeto de uma Rede Geodésica para Monitoramento da Subsidência na Planície Deltaica do Rio São Francisco.

A proposta para implantação da rede está fundamentada nos estudos realizados em toda planície deltaica e seu entorno durante o desenvolvimento de atividades de pesquisa entre os anos de 2013 e 2017 sendo complementado por estudos geológicos anteriores a este período. Essas atividades contribuíram para a elaboração de um banco de dados geoespaciais com uma variedade de informações da área de estudo que proporcionaram os requisitos essenciais para o dimensionamento geométrico e a disposição dos 26 vértices geodésicos que compõem a rede geodésica de monitoramento. (Figura 16).

O conjunto de monumentos é composto por alguns marcos de RN do SGB/IBGE, marcos geodésicos da rede do Baixo São Francisco/CHESF e alguns marcos implantados nas campanhas de levantamentos pela equipe do Laboratório de Estudos Costeiros da UFBA (LEC/UFBA).

A rede geodésica de monitoramento, proporcionará apoio às atividades de pesquisa na região. Toda estrutura implantada e as informações estão organizadas para a realização da mensuração dos processos de subsidência na planície.

\section{CONCLUSÕES}

Os processos de subsidência foram avalidados a partir do posicionamento por geodesia espacial, em síntese, aspectos geológicos foram abordados e as movimentações da superfície foram investigadas. Em algumas regiões foram identificados indícios de rebaixamentos acentuados.
As avaliações dos perfis longitudinais apontaram algumas ocorrências de rebaixamentos de superfície na planície deltaica ao analisar a topografia dos cordões litorâneos holocênicos.

Além das ocorrências localizadas, foi verificado um rebaixamento de alguns cordões à 
medida que os mesmos se aproximam do Rio São Francisco, com uma maior intensidade no entorno da sede do município de Piaçabuçu-AL. Esse rebaixamento, por sinal, pode também ser verificado ao longo da rodovia AL 101 no trecho Penedo-Piaçabuçu, onde 5 vértices de $\mathrm{RN}$ do SGB/IBGE foram implantados sobre os cordões litorâneos (RN 2487T, 2487U, 2487V,2487X, 2487Z). Suas respectivas altitudes $(5,993 \mathrm{~m}$; 5,499 m; 3,789 m; 3,612 m e 3,525 m) também apontam uma redução significativa de nível à medida em que se aproxima da sede de Piaçabuçu-AL, uma evidência de que nessas imediações houve o rebaixamento da superfície no Holoceno.

As altitudes localizadas nas imediações da foz de um delta geralmente são inferiores àquelas dos seus flancos, isso ocorre devido a ação marinha ser mais intensa nas imediações da desembocadura, ainda assim, os rebaixamentos identificados ao longo das margens a montante do rio, superariam essa premissa, já que os desníveis são relativamente elevados.

A rede geodésica projetada dará suporte ao monitoramento da subsidência em toda a planície deltaica. Com a implantação em definitivo da rede de monitoramento, a expectativa é que seja iniciado um projeto contínuo de coleta de dados geodésicos a partir de campanhas periódicas de rastreios GNSS nos 26 vértices. Essas informações darão contribuições para a determinação das taxas de subsidência na planície deltaica modelando suas tendências a médio e longo prazo

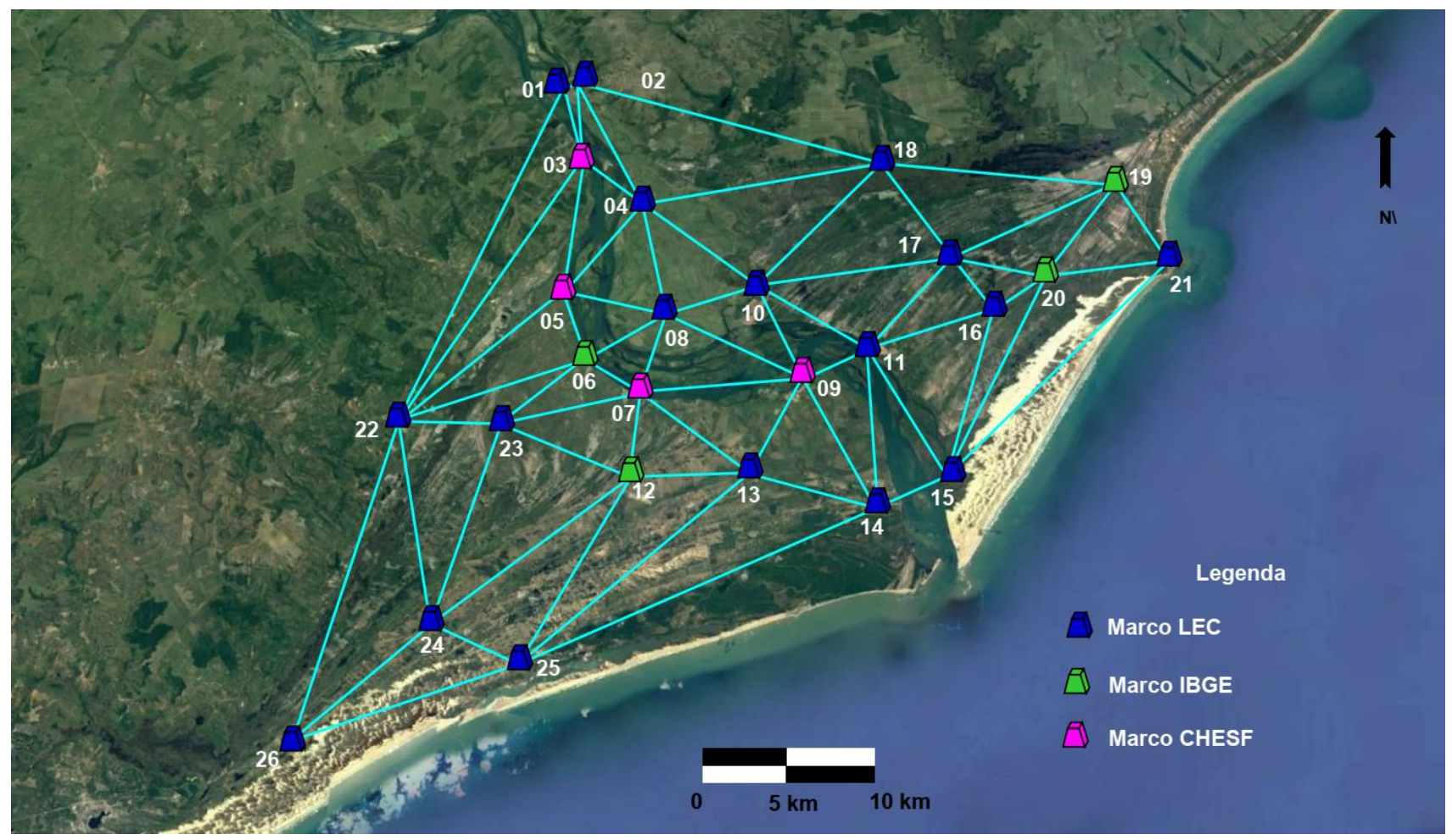

Figura 16 - Rede geodésica para monitoramento da subsidência do Delta do São Francisco.

\section{AGRADECIMENTOS}

Os autores agradecem às instituições que colaboraram diretamente com a concessão de dados e disponibilização de softwares, equipamentos ou laboratórios: Universidade Federal da Bahia através do Departamento de Engenharia de Transportes e Geodésia e o Departamento de Sedimentologia; Universidade Federal de Pernambuco através do Departamento de Engenharia Cartográfica; Instituto Brasileiro de Geografia e Estatística por meio da Coordenação de Geodésia e a Agencia Espacial Europeia.

\section{REFERÊNCIAS}

BALDI, P.; CASULA, G.; CENNI, N.; LODDO, F.; PESCI, A. GPS-based monitoring of land subsidence in the Po Plain (Northern Italy). Earth and Planetary Science Letters, v. 288, n. 1, p. 204-212, 2009.

BARBOSA, L.M. \& DOMINGUEZ, J.M.L. Coastal dune fields at the São Francisco river strand plain, northeastern Brazil: morphology and environmental controls. Earth Surface Processes and Landforms, v. 29, p. 443-456, 2004.

BARBOSA, L.M. Quaternário costeiro no Estado de Alagoas: influências das variações do nível do mar. Salvador, 1985. 55 p. Dissertação (Mestrado em Geologia), Instituto de Geociências, Universidade Federal da Bahia. 
BARBOSA, L.M.; BITTENCOURT, A.C.S.P.; DOMINGUEZ, J.M.L.; MARTIN, L. The Quaternary deposits of the state of Alagoas: influence of the relative sea level changes. In QUATERNARY OF SOUTH AMERICA AND ANTARCTICA PENINSULA 4, JO Rabassa (ed.). Balkema: Rotterdam; p. 269-290, 1986.

BITTENCOURT, A.C.S.P.; DOMINGUEZ, J.M.L.; MARTIN, L.; FERREIRA, Y.D.A. Dados preliminares sobre a evolução do delta do Rio São Francisco (SE/AL) durante o Quaternário: influência das variações do nível do mar. In: SIMPÓSIO DO QUATERNÁRIO NO BRASIL, IV, Rio de Janeiro, 1982. Atas...Rio de Janeiro: Sociedade Brasileira de Geologia, 1982, p. 49-62.

BITTENCOURT, A.C.S.P.; MARTIN L.; DOMINGUEZ, J.M.L. Evolução paleogeográfica quaternária da costa do estado de Sergipe e costa sul do estado de Alagoas. Revista Brasileira Geociências, v. 13, n. 2, p. 93-97, 1983.

DOMINGUEZ, J.M.L. \& ARAÚJO, L.M. Formação Barreiras: o registro de um onlap costeiro durante o Mioceno. In: CONGRESSO BRASILEIRO DE GEOLOGIA, 44. Curitiba. 2008. Anais...Curitiba: Sociedade Brasileira de Geologia, 2008, p. 613.

DOS SANTOS, S.M.; CABRAL, J.J.D.S.P.; DA SILVA PONTES FILHO, I.D. Monitoring of soil subsidence in urban and coastal areas due to groundwater overexploitation using GPS. Natural hazards, v. 64, p. 421-439, 2012.

DREWES, H. \& HEIDBACH, O. The 2009 horizontal velocity field for South America and the Caribbean. In: GEODESY FOR PLANET EARTH. Springer Berlin Heidelber. p. 657-664, 2012.

GOOGLE. Base Cartográfica. Disp. em: <https://www.google. com.br/maps>. Acessado em: 01/03/2018

GUIMARÃES, J.K. Evolução do delta do Rio São Franciscoestratigrafia do Quaternário e relações morfodinâmicas. Salvador, 2010. 127 p. Tese (Doutorado em Geologia) Instituto de Geociências, Universidade Federal da Bahia.

IBGE - INSTITUTO BRASILEIRO DE GEOGRAFIA E ESTATÍSTICA. 2010. Sistema de Interpolação de Ondulação Geoidal (MAPGEO2010). Disp. em:< http://www.ibge.gov.br/home/geociencias/geodesia/modelo_g eoidal.shtm>. Acesso: Dez/2014.

LEÃO, Z.M. \& DOMINGUEZ, J.M. Tropical coast of Brazil. Marine Pollution Bulletin, v. 41, p. 112-122, 2000.

LEICK, A., RAPOPORT, L., TATARNIKOV, D. GPS satellite surveying. John Wiley \& Sons. 840 p., 2015.

MARJANOVIĆ, M.; BAČIĆ, Ž.; BAŠIĆ, T. Determination of horizontal and vertical movements of the Adriatic microplate on the basis of GPS measurements. In: GEODESY FOR PLANET EARTH. Springer Berlin Heidelberg, p. 683-688, 2012, Buenos Aires.

MARTIN, L.; FLEXOR, J.M.; VILAS BOAS, G.S.; BITTENCOURT, A.C.S.P.; GUIMARÃES, M.M.M. Courbe de variation du niveau relatif de la mer au cours des 7000 dernières années sur un secteur homogène du littoral brésilien (Nord de Salvador-Bahia). In: INTERNATIONAL SYMPOSIUM ON COASTAL EVOLUTION IN THE QUATERNARY SHORELINES, São Paulo. 1979. Actas... São Paulo, 1979, p. 264-271.

MONICO, J. Posicionamento pelo GNSS. Descrição, fundamentos e aplicações. Editora UNESP. $2^{a}$ edição. São Paulo, 476 p., 2008.

MONICO, J.F.G. Posicionamento por Ponto de Alta Precisão: Uma Ferramenta para a Geodinâmica. Revista Brasileira de Geofísica, v. 18, p. 1-10, 2000.

PONTE, F.C. Estudo morfoestrutural da Bacia Sergipe-Alagoas. Boletim Técnico da PETROBRAS, v. 12, n. 3, p. 439-474, 1969.

SATO, H.P.; ABE, K.; OOTAKI, O. GPS-measured land subsidence in Ojiya city, Niigata prefecture, Japan. Engineering Geology, v. 67, n. 3, p. 379-390, 2003.

SEEBER, G. Satellite geodesy: foundations, methods, and applications. Walter de Gruyter, 612p., 2003.

SILVA, E.F.; MIRANDA, C.D.M.; MONICO, J.F.G. O Uso de Receptores GPS no Monitoramento Planimétrico na UHE Luiz Eduardo Magalhaes. In: SEMINÁRIO NACIONAL DE GRANDES BARRAGENS, XXX, Foz do Iguaçu, 2015. Atas...Foz do Iguaçu.

SONG, D.S. \& YUN, H.S. Crustal Deformation Velocities Estimated from GPS and Comparison of Plate Motion Models. Journal of The Korean Society of Civil Engineers, v. 26, n. 5D, p. 877-884, 2006.

SOUZA, W.O. Modelagem do movimento da placa tectônica sul-americana por meio de dados VLBI e GNSS. Recife, 2013. 179 p. Dissertação (Mestrado em Ciências Geodésicas), Universidade Federal de Pernambuco.

STECKLER, M.S.; MONDAL, D.R.; NOONER, S.L.; AKHTER, S.H.; SEEBER, L.; BETTADPUR, S.V.; RANGIN, C. GPS velocity field in Bangladesh: Delta subsidence, seasonal water loading and shortening across the Burma Accretionary Prism and Shillong Massif. In: AGU FALL MEETING San Francisco. 2013. Abstracts... San Francisco, 2013, v. 1, p. 2566

TEIXEIRA, N.N. Análise geodésica de deformações da crosta em regiões de grandes barragens a partir de deslocamentos tridimensionais obtidos pelo sistema de posicionamento global. Curitiba, 2005. 268 p. Tese (Doutorado em Ciências Geodésicas) -Universidade Federal do Paraná.

TORGE, W. \& MÜLLER, J. Geodesy. Walter de Gruyter. 529 p., 2012.

VILLWOCK, J.A.; TOMAZELLI L.J.; LOSS E.L.; DEHNHARDT, E.A.; HORN, N.O.; BACHI, F.A., DEHNHARDT, B.A. Geology of the Rio Grande do Sul Coastal Province. In: QUATERNARY OF SOUTH AMERICA AND ANTARCTICA PENINSULA, 4. Rotterdam. 1986. Rabassa, J.O. ed. Balkema: Rotterdam, 1986, p. 79-97.

YUILL, B.; LAVOIE, D.; REED, D.J. Understanding subsidence processes in coastal Louisiana. Journal of Coastal Research, v. 1, p. 23-36, 2009. 